\title{
FORMULA FOR THE WELL-BEING OF EXPERIMENTAL ANIMALS: 3R + 1R
}

\author{
Nikola M. Stojanovic ${ }^{1 *}$, Milica M. Todorovska ${ }^{1,2}$ \\ ${ }^{1}$ Faculty of Medicine, University of Niš, Niš, Serbia \\ ${ }^{2}$ Department of Chemistry, Faculty of Science and Mathematics, University of Niš, Niš, Serbia
}

\begin{abstract}
Animals were first used for research purposes at the beginning of the development of both biology and medicine. However, the expansion in the use of animals for laboratory purposes began in the 19th century. During an experiment, animals may experience fear, deprivation, disease, and various degrees of pain. Animal Protection activists oppose to animal experiments and it is, therefore, necessary to harmonize the worldwide regulations on the use of animals for scientific purposes. More than 50 years ago, Russell and Burch were the first to define the $3 R$ rule. It consists of the following three principles: Replacement, Reduction and Refinement. Over time, one more $R$ was added to stand for Responsibility, meaning a responsible behavior of those who implement the $3 R$ rule. Replacement means that, if possible, each experimental animal model should be replaced by an in vitro method or be reduced to a smaller number of animals used. Reduction is defined as a reduced number of animals used to obtain certain experimental information, while Refinement is a reduction in the frequency or severity of inhumane procedures applied to animals that have yet to be used. The $3 R(+1 R)$ rule has its drawbacks, but it is a very important aspect of animal use regulation, which is essential. These rules are used to direct animal users towards an adequate experimental model, but also to be a reminder of the appropriate use of experimental animals at a given time.
\end{abstract}

Key words: experimental animals, ethics in biomedicine, $3 R+1 R$ rule.

\section{Experimental Animals}

The use of animals for research purposes began at the dawn of science (more specifically of biology and medicine). However, in the $19^{\text {th }}$ century, together with the development of a new scientific discipline called physiology, the true expansion of animal use for laboratory purposes began [1]. During the $18^{\text {th }}$ and $19^{\text {th }}$ century, anesthetics were not administered to animals during experiments, although diethyl ether (the first anesthetic) and its potential action had been known to science since the $16^{\text {th }}$ century [1]. A series of experiments on non-anesthetized animals led to the establishment of the Royal Committee in the UK. This committee adopted the first law to regulate the issue, the Cruelty to Animals Act in 1876 in order to limit/control the use of animals in experiments [2].

The list of experimental animals available for use in scientific experiments today contains a large number of lower vertebrates and invertebrates (Table 1), as well as non-human primates (Table 2) [3].

Among these animals (Table 1 and 2), mice are by far the ones used most frequently due to a high degree

\footnotetext{
* Correspondence to: Nikola M. Stojanović, M.D., PhD Student Faculty of Medicine, University of Niš, Bulevar dr Zorana Đindjića 81, 18000 Niš, Serbia

Phone: +381628049212

E-mail: nikola.st90@yahoo.com

Received January $24^{\text {th }}, 2017$, accepted for publication May $30^{\text {th }}, 2017$
}

of their biological similarity to humans, easy handling and a short reproductive cycle. Nowadays, in the era of genetic manipulations, mice with specific genetic codes, that mimic some of the disorders found in humans, are an excellent experimental model [4]. A large number of researchers base their research, which eventually leads to the discovery of new drugs and/or efficacy of pharmaceutical products and vaccines, on in vivo experimental animal models. Likewise, many researchers cannot even imagine a clinical trial without the initial toxicity testing performed on animals (mouse, rat, etc.) [5]. During the development of science, some of the breakthroughs would not have occurred had it not been for animal experiments. A certain_number of scientific discoveries were incorrect and/or were "slowed down" due to previous studies on experimental animals [6,7]. The use of experimental animals led to the revolutionary breakthroughs in the $17^{\text {th }}$ century and these included the discovery of the circulatory system, antibodies, effects of hormones and vitamins, mechanisms of nerve impulses, a large number of genes associated with hereditary diseases, numerous medications and their effects, organ transplantation, etc. [6]. However, there were cases where despite the positive outcomes from animal experiments, results could not be transferred to humans. For instance, in the case of thalidomide, for instance, the drug had passed all the stages of animal testing and no side effects had been reported, however, in infants born to the mothers who used thalidomide the agent caused aplasia of the extremities. On the other hand, various other 
Table 1 Some of the lower vertebrates and invertebrates most frequently used in experiments

\begin{tabular}{llll}
\hline Name & Latin name & Name & Latin name \\
\hline Mouse & Mus musculus & Rabbit & Oryctolagus cuniculus \\
Rat & Rattus norvegicus & Dog & Canis familiaris \\
Guinea pig & Cavia porcellus & Cat & Felis catus \\
Syrian hamster & Mesocricetus auratus & Frog & Xenopus (laevis, tropicalis) and Rana (temporaria, pipiens) \\
Chinese hamster & Cricetulus griseus & Zebrafish & Danio rerio \\
Mongolian gerbil & Meriones unguiculatus & & \\
\hline
\end{tabular}

breakthroughs have not resulted from the use of experimental animals and these include the inventions of stethoscope, penicillin, artificial respiration, computed tomography, HIV virus, etc. [7].

Table 2 Some of the non-human primates most frequently used in experiments

\begin{tabular}{ll}
\hline Name & Latin name \\
\hline Marmoset & Callithrix jacchus \\
Macaque monkey & Macaca fascicularis \\
Rhesus monkey & Macaca mulatta \\
Baboon & Papio sp. \\
\hline
\end{tabular}

During an experiment, animals may experience fear, deprivation, disease and pain of various degrees. These may occur both separately and in combination, under a variety of experimental conditions. However, they may be absent altogether. Thus, for example, mice that are tied up experience temporary fear, while those injected with a pathogen besides experiencing temporary fear and mild pain from inoculation, also develop a disease during the period of observation [8]. A number of different systems (scales) have been proposed to help in the assessment of the degree of invasiveness and severity of experimental procedures. One of these, proposed by the British Laboratory Animal Association, classifies the seriousness of some procedures as minimum, intermediate and maximum [9]. In order to obtain the corresponding score, this scaling takes into account the degree of animal alertness, the method of injection of a drug/tested sample, sampling of different tissues from live animals and certain surgical procedures on animals.

Do animals feel pain? This is a big dilemma among the scientists and a large number of them agree that animals do feel pain. Great philosophers, such as Bentham, advocated the view that even though animals cannot discern or speak, they, nevertheless, can feel pain [1]. The International Association for Pain defines pain as "unpleasant sensory and emotional experience associated with real or potential tissue damage, or caused by such a damage or injury" [10]. Therefore, if we know that there is a difference between pain and nociception, that pain can occur without nociception, and that emotions are one of the mental functions that characterize a conscious person, the question of whether animals feel pain is raised again.

\section{Ethical Problems and Regulation of Animal Use in Experiments}

Despite the progress of biomedical research and the benefits for humanity achieved by experimental research, the concerns related to animal experiments have always existed. It has a long history, starting with the letters of protest and peaceful gatherings, to the more aggressive outcries in recent times, primarily in Europe and America [6]. According to the animal rights activists, each experiment involving the use of animals potentially breaks six widely accepted moral norms: respect for the animals, good scientific practice, being a good citizen, responsibility to future generations, environmental responsibility, respect for the lifestyle and religion of other people.

Bringing up animals in cages, special diets, treatment of animals in experiments and their sacrifice in the end, grossly endangers a specific way of life of a biological species. Causing pain, suffering, anxiety, and in recent times the manipulation with animal genome constitute disrespect of life itself. Toxicity testing on animals is the most controversial one due to the belief that it is unnecessary to test so many compounds. Although not all animals suffer during these tests (e.g. control groups or experimental groups which receive a low dose of the tested substance), a large number of animals is subjected to suffering due to inherent characteristics of toxicity testing to cause undesirable effects in animals $[6,11]$.

There is a growing tendency of resolving the above ethical problems related to the use of animals in scientific research in a satisfactory way. There are many national and international bodies commissioned to care and responsibility for the welfare of animals in experiments. This concept is called "a responsible experiment". Among the first institutions that should be mentioned here is the International Committee for Laboratory Animal Science (ICLAS), involving more than 100 countries, with the headquarters in the United States. This Committee has set the international guidelines for experimental procedures and trainings for researchers [12]. In Canada, animal experiments are regulated by the Canadian Council on Animal Care (CCAC), a national organization founded in 1968 in Ottawa. Its goal is simple: "work to improve the care of animals in Canada" [13]. In India, several institutions are concerned with the welfare of experimental animals, in both state and private sectors. The National Center for Laboratory Animal Sciences (NCLAS) in Hyderabad and the Central Drug Research Institute in Lucknow, regulate this segment of science, both primarily through legislation. The guidelines 
published by NCLAS in 1992 and amended in 2000 should be addressed as well. They regulate the way of animal handling during the experiments [6]. The South African Medical Research Council (SAMRC) recognizes the moral dilemma involved in the use of animals in experiments, in teaching and testing, and the Council is committed to support only the projects that promise progress in science and knowledge and bring about certain benefits to the mankind, animals, and to the environment [8].

On November $24^{\text {th }} 1986$, the European Parliament and the Council of the European Union (EU) adopted the first Directive 86/609/EEC in order to eliminate the differences across the laws and regulations of the EU countries concerning the use of animals for experimental purposes [3]. The European Parliament and the EU Council adopted the directive on the protection of animals used for scientific purposes in 2010 [3]. In this extensive and comprehensive document, the EU refers to the reduction and replacement of animals in experiments; the origin, method of conservation, nutrition and care; ways of handling animals by laboratory staff and researchers and, most importantly, the requirement for the evaluation and pre-approval of projects and experiments in which animal use for research purposes is planned.

Our country (the Republic of Serbia) adopted the first Animal Welfare Act as late as 2009. This Act regulates a number of important issues for the preservation and improvement of animal welfare in various situations, including the use of animals in experiments [14]. This law stipulates the conditions (in terms of the purpose, area and ways of performing the experiments, authorized persons to carry out experiments, as well as the animals themselves) that must be met for conducting experiments on animals that would be considered legitimate. This law subsumes all living vertebrates and invertebrates under the concept of experimental animals, as well as their developing forms to be used in experiments [15].

The Veterinary Practice Act regulates that scientific experiments on animals can only be carried out by experts in veterinary, medical, pharmaceutical and other research institutions, and that the animals should not be subjected to any ill-treatment or suffering during the experiments [16]. Animal experiments can be performed only by the physical and legal entities registered in the Animal Experiments Registry kept by the competent Ministry. The persons and/or institutions entered in the Registry can perform such experiments only if they possess the certificate of approval to perform experiments on animals. This certificate is issued by the Minister, based on the expert opinion of an Ethics Committee in order to safeguard and upkeep the welfare of experimental animals, in accordance and in response to the previously submitted request of such individuals/ institutions. The law prescribes the content of such a submission or request [17].

\section{R Rule}

More than 50 years ago, Russell and Burch [18] were the first to define the $3 \mathrm{R}$ rule. It consists of three principles Replacement, Reduction and Refinement. This rule has been modified (perfected) over the years to gain its current form. It still consists mainly of the 3Rs, but another R has been added as well - Responsibility. This concept, responsibility, stipulates that those who implement the $3 \mathrm{R}$ rule should be held liable for their actions and behavior in the experiments they are performing [19].

\section{Replacement}

Each experimental model that can be replaced and/or leads to the reduction of the number of animals represents an alternative method of animal testing. Nowadays, there is a tendency to get as many details as possible from an animal (or group of animals) in order to avoid the experiment repetition, which can be achieved with a good experiment prediction [20]. This can also be achieved by a cost-benefit analysis of the experiment [21]. The difference in the replacement of experimental animal models exists for different types of research (applied, fundamental and innovation), due to the requirement to have a validated alternative method when engaging in applied research. The methods of replacement can be as follows: absolute (where animals are completely excluded from the experiment) and relative (the use of lower vertebrates and invertebrates), direct (using isolated human material or the one from dead animals) or indirect (the use of other means of carrying out the same experiment), as well as total (human models and in vitro methods) or partial (nonanimal models) [6].

When contemplating on a replacement, a question should be answered whether this is an adequate replacement. If so, we are encountering difficulties with the validation of the replacement method. This problem is particularly evident in the attempts to replace animals in toxicological studies, but recent findings suggest a potential new, alternative in vitro model [5]. This refers particularly to the models that evaluate the carcinogenic potential of a compound [22]. We are presenting here only some of the suggestions for the application of replacement principle:

1) Animal and plant tissues culture - in in vitro conditions, different cell populations mimic in vivo conditions (cultured kidney cells, liver cells, lymphocytes etc.),

2) Isolated organ methods - the contraction of smooth muscles of the gastrointestinal tract, the hippocampus function testing in the brain tissue sections,

3) In vitro methods (reactions) - various chemical/ biochemical reactions which mimic isolated reaction processes in an organism (enzyme inhibition/ activation),

4) Computerized simulation - the use of computer programs for biomolecule interaction with certain receptors simulation; (Q)SAR experiments [23]. 


\section{Reduction}

Reduction is defined as: "a reduction in the number of animals used in order to obtain certain information". Similar to other "Rs", reduction serves to reduce the number of animals, where possible, and eliminate the suffering and inhuman treatment of animals [24]. The Principles do not define the reduction as minimization of the number of animals used to obtain certain information. The reduction is defined simply as a decrease, which is not synonymous with minimization. Russell and Burch do not explain why reduction is not defined as a minimization of the animal number, since their goal is to minimize animal pain. However, if we could define reduction as minimization, then simply the reduced number of experimental animals in a given experiment or the type of research would not be reduction, unless absolutely the smallest number of animals is used to obtain the desired results. Russell and Burch emphasize that it is often impossible to know the minimal number of animals needed before the experiment is carried out. Speaking of the importance of using statistical methods in the reduction, they state that: "For the purpose of reducing, as we have noted, statistical methods play a key role - they give the minimum number of animals needed for the experiment".

In addition to a simple reduction of the number of animals used, the reduction can be achieved in many other ways as well. Good experimental design and statistical analysis are to ensure that researchers are using the optimal number of animals. If kept in a clean environment, the animals suffer less from disease or secondary infections that can interfere with the study, thus reducing the number of animals more readily attained. New scanning techniques mean that tumors can be traced in a non-invasive manner, with more data collected from the same animal [25].

At first glance, it seems that the reduction is an easily measured target - it comes down to count. The data available to us, however, show that there is no progress in reducing the total number of animals used for experimental purposes, despite the researchers' efforts. On the contrary, this number has been steadily rising since the 1990s [26]. The explanation for this failure is often simple, and its reason lies in the implementation of more biomedical research. Today, many rodents and fish are counted in the total number of laboratory animal experiments, even if they are only used as breeding species to produce better animal models for the testing of serious diseases such as heart disease, cancer or Alzheimer's disease. These animals can also be used as a substitute for other animals, such as monkeys and dogs. The advantage of reduction is certainly the reduction of the number of animals exposed to manipulation, discomfort and suffering, but we must not forget to mention its deficiencies. In the first place, insufficient numbers of experimental animals may produce unreliable and inaccurate results. This disadvantage could be nullified by detailed study planning [24].

\section{Refinement}

Russell and Burch define refinement as "any reduction in the frequency or severity of inhumane procedures applied to animals that have yet to be exploited". This involves stress reduction to an absolute minimum. Any simple improvement in the animal housing/keeping conditions and animal care during the study means a great deal. This improvement can often be achieved through "environmental enrichment", meaning that the animals live a better, less stressful life. Additionally, this improvement increases the reliability of research results. There are numerous specific improvement techniques and they can be applied in almost all aspects of animal life. For example, a food reward can be used to train a monkey to sit on the measurement scales and thus completely eliminate the stress that the animal is experiencing. Blood pressure, heart rate and activity levels can be measured via an implant, so that animals do not have to be restrained on several occasions. Rodents can be placed in a special red plastic "house", so that they are under the impression of being in a dark place (they cannot see through red materials) and one can observe and study them. Animals should be routinely kept in groups and in stimulating environments as well. Animal welfare is not only an ethical concept, but it also represents good science. It is also against the law for any researcher to cause undue suffering to any animal.

Nowadays, when applying for an experiment to the Ethics Committee (or other relevant bodies) the principle of improving the living conditions of laboratory animals is taken into account. The study of Hagelin and associates has shown that in Sweden, as much as $18 \%$ of the applications to the Ethics Committee are refused and/or a modification of the study protocol is asked for. These modifications are commonly referred to as "improvements". The most common requirements include the design of the study, euthanasia and animal housing [27]. Moreover, there has been an increase in the requested amendments related to animal anesthesia and the presence of a licensed supervisor during the experiment [27].

\section{R - Responsibility}

Another, newer, concept in the $3 \mathrm{R}$ rule is the fourth $\mathrm{R}$ (4R). This $\mathrm{R}$ refers to the responsibility imposed as necessary to comply with the $3 \mathrm{R}$ rule [19]. Researchers and people in general who use experimental animals and those who grow them and care about them are considered responsible for the proper care and animal use. Also, responsibility is directly connected to the level of training (to work with/handle animals) of that specific individual. The expertise of the persons carrying out the experiment should also be taken into account, meaning that it is necessary that they thoroughly know proper animal handling techniques. On the other hand, it is essential that the performed experiments are adequately substantiated in the relevant literature, i.e. that the experiments result in sufficiently relevant and significant scientific information [8]. This 
rule also applies to the rehabilitation of animals which survived the experiment, i.e. their further destiny. They can be reused in another experiment if the treatment (or control group) and the experiment did not cause any permanent damage [8].

Even Russell and Burch gave an example of how it is possible to implement the $3 \mathrm{R}$ rule adequately. They exploited as an example the use of animals in virological analyses [28]. One animal is sufficient for obtaining large amounts of tissue for in vitro experiments - the replacement. Moreover, by the use of just one animal it is possible to acquire sufficient amount of information and a large number of animals is then not required. This concept fits in the reduction principle. Finally, the animals used in the experiment could be painlessly killed and would not have to experience the symptoms of disease arising from virus inoculation - refinement. We can now add the $4^{\text {th }} \mathrm{R}$, which involves a degree of responsibility of the researcher who conducts experiments on animals.

\section{References}

1. Flecknell P. Replacement, reduction and refinement. Altex 2002; 19:73-8.

2. Orlans BF. In the Name of Science. Oxford: Oxford University Press, 1993.

3. Council Directive $86 / 609 /$ EEC of 24 November 1986 on the approximation of laws, regulations and administrative provisions of the Member States regarding the protection of animals used for experimental and other scientific purposes http://eurlex.europa.eu/LexUriServ/LexUriServ.do?uri=CELEX:31986L060 9:en:HTML

4. Gargiulo S, Greco A, Gramanzini M, et al. Anesthesia, analgesia, and care, Part I: anesthetic considerations in preclinical research. ILAR J 2012; 53:E55-69.

5. Holmes A, Creton S, Chapman K. Working in partnership to advance the 3Rs in toxicity testing. Toxicology 2010; 267:14-19.

6. Giridharan NV, Kumar V, Muthuswamy V. Use of Animals in Scientific Research. Indian Counc Med Res 2000; 1-27.

7. Mandal J, Parija SC. Ethics of involving animals in research. Trop Parasitol 2013; 3:4-6.

8. Austin JC. Guidelines for Ethics in Medicinal Research: Use of Animals in Research and Trainig. South African Medical Council, 2004.

9. Wallace J, Sanford J, Smith MW, Spencer KV. The assessment and control of the severity of scientific procedures on laboratory animals. Laboratory Animals 1990; 24:97-130.

10. Radulović N, Blagojević P, Ranđelović P, Stojanović N. The Last Decade of Antinociceptive Alkaloids: Structure, Synthesis, Mechanism of Action and Prospect. Curr Top Med Chem 2013; 13:2134-2170.

11. Inglis JK. Introduction to laboratory animal science and technology. Oxford: Pergamon Press, 1980.

12. World Health Organization and International Council for Laboratory Animal Science. Guidelines for Breeding and Care of Laboratory Animals, 1993.

13. Olfert ED, Cross MB, McWilliam AA. Guide to the care and use of experimental animals. Canadian Council on Animal Care, 1993.

14. Čl. 1. Zakon o dobrobiti životinja, „Službeni glasnik RS“, br. 41/2009.

\section{Conclusion}

In the end, a remark should be made that $3 R(+1 R)$ principle has its shortcomings, e.g. these rules do not allow the use of certain animals (e.g. chimpanzees) in situations where it is acceptable and the usefulness of that is clearly visible. In addition, a situation may arise when two $\mathrm{R}$ rules cannot be applied at the same time because they nullify one another, e.g. in an attempt to decrease the use of animals through the possibility of animal re-use on one side, with an effort to decrease the experienced stress/pain occurring during the experiment on the other. Putting aside any personal attitudes towards the $3 \mathrm{R}(+1 \mathrm{R})$ rules, one can not diminish their significant impact on the regulation of animal use that is most certainly needed. These rules attempt to guide a researcher towards an adequate experimental model and to remind us how to use experimental animals at a given moment.

Acknowledgment: The authors are grateful to professor $d r$ Dušica Pavlović for her patience and suggestions during the writing of this paper.

15. Čl. 5. st. 1. tačka 30, Zakon o dobrobiti životinja, ,Službeni glasnik RS“, br. 41/2009.

16. Čl. 138. st. 5. Zakon o veterinarstvu, „Službeni glasnik RS“, br. 91/2005 i 30/2010.

17. Batrićević A. Etički i pravni okviri za zaštitu dobrobiti eksperimentalnih životinja u Republici Srbiji. Glasnik Advokatske komore Vojvodine 2012; 11:726-751.

18. Russell WMS, Burch RL. The Principles of Humane Experimental Technique. London, 1959.

19. Vučinić M. Basic principles of experimental animals welfare protection. Vet glas 2007; 61:173-181.

20. Madden JC, Hewitt M, Przybylak K, Vandebriel RJ, Piersma AH, Cronin MT. Strategies for the optimisation of in vivo experiments in accordance with the 3Rs philosophy. Regul Toxicol Pharmacol 2012; 63:140-54

21. Graham ML, Prescott MJ. The multifactorial role of the 3 Rs in shifting the harm-benefit analysis in animal models of disease. Eur J Pharmacol 2015; 759:19-29.

22. Annys E, Billington R, Clayton R, et al. Advancing the $3 R$ s in regulatory toxicology - Carcinogenicity testing: Scope for harmonisation and advancing the $3 \mathrm{Rs}$ in regulated sectors of the European Union. Regul Toxicol Pharmacol 2014; 69:234-242.

23. Hakkinen PJ, Green DK. Alternatives to animal testing: Information resources via the Internet and World Wide Web. Toxicology 2002; 173:3-11.

24. Tannenbaum J, Bennett B. T. Russell and Burch's 3Rs Then and Now: The Need for Clarity in Definition and Purpose. J Am Assoc Lab Anim Sci 2015; 54:120-132.

25. Russell WMS, Burch RL. The Principles of Humane Experimental Technique. 2nd ed. London: Methuen UFAW, 1992

26. Ormandy EH, Weary DM, Griffin G. Public views on the use of animals in science. Universities Federation for Animal Welfare (UFAW) Symposium. York, UK, June 30, 2010.

27. Hagelin J, Hau J, Clarsson HE. The refining influence of ethics committees on animal experimentation in Sweden, Lab Anim 2003; 1:10-18.

28. Sanders FK. Tissue Cultures as Substitutes for Experimental Animals. Coll Papers Lab Animals Bur 1957; 6:35-44. 